\title{
Volatile composition and classification of Lilium flower aroma types and identification, polymorphisms, and alternative splicing of their monoterpene synthase genes
}

\author{
Fang Du1, Ting Wang ${ }^{1}$, Jun-miao Fan ${ }^{1,2}$, Zhi-zhi Liu', Jia-xin Zong ${ }^{1}$, Wei-xin Fan ${ }^{3}$, Yuan-huai $\operatorname{Han}^{4}$ and \\ Donald Grierson ${ }^{5,6}$
}

\begin{abstract}
Lily is a well-known ornamental plant with a diversity of fragrant types. Basic information on lily floral scent compounds has been obtained for only a few accessions, and little is known about Lilium aroma types, the terpene synthase genes that may play roles in the production of key volatiles, or the range of monoterpenes that these genes produce. In this study, 41 cultivars were analyzed for volatile emissions, and a total of 46 individual volatile compounds were identified, 16 for the first time in lilies. Lily accessions were classified into six groups according to the composition of major scent components: faint-scented, cool, fruity, musky, fruity-honey, and lily. Monoterpenes were one of the main groups of volatiles identified, and attention was focused on terpene synthase (TPS) genes, which encode enzymes that catalyze the last steps in monoterpene synthesis. Thirty-two candidate monoterpene synthase cDNAs were obtained from 66 lily cultivars, and 64 SNPs were identified. Two InDels were also shown to result from variable splicing, and sequence analysis suggested that different transcripts arose from the same gene. All identified nucleotide substitution sites were highly correlated with the amounts of myrcene emitted, and InDel site 230 was highly correlated with the emission of all major monoterpenoid components, especially (E)- $\beta$-ocimene. Heterologous expression of five cDNAs cloned from faint-scented and strong-scented lilies showed that their corresponding enzymes could convert geranyl diphosphate to (E)- $\beta$-ocimene, $a$-pinene, and limonene. The findings from this study provide a major resource for the assessment of lily scent volatiles and will be helpful in breeding of improved volatile components.
\end{abstract}

\section{Introduction}

Floral scents have attracted the attention of people from ancient times; they are widely used in perfumes, food flavorings, and cosmetics, and in addition to flower color, they form the basis of important commercial traits of ornamental plants. However, fragrance has often been

Correspondence: Fang Du (Fang.du@wur.nl) or Donald Grierson

(Donald.Grierson@nottingham.ac.uk)

${ }^{1}$ College of Horticulture, Shanxi Agricultural University, 030801 Taigu, Shanxi, China

${ }^{2}$ College of Horticulture, Nanjing Agricultural University, 210095 Nangjing

Jiangsu, China

Full list of author information is available at the end of the article. overlooked in breeding, and many fragrance traits have been lost over time due to artificial selection ${ }^{1}$. Detailed molecular genetic analysis can ameliorate some drawbacks of classical plant breeding ${ }^{1}$ and has been utilized in plants such as petunia and snapdragon, which have been used as models for investigating the synthesis and regulation of fragrance ${ }^{2}$. To facilitate the genetic improvement of fragrance, either by genetic engineering or marker-assisted breeding, basic qualitative and quantitative information on floral fragrance composition and quality and expression of related genes is required. Floral volatile profiling has been carried out with many scented

\section{(c) The Author(s) 2019}

(c) Open Access This article is licensed under a Creative Commons Attribution 4.0 International License, which permits use, sharing, adaptation, distribution and reproduction cc) in any medium or format, as long as you give appropriate credit to the original author(s) and the source, provide a link to the Creative Commons license, and indicate if changes were made. The images or other third party material in this article are included in the article's Creative Commons license, unless indicated otherwise in a credit line to the material. If material is not included in the article's Creative Commons license and your intended use is not permitted by statutory regulation or exceeds the permitted use, you will need to obtain permission directly from the copyright holder. To view a copy of this license, visit http://creativecommons.org/licenses/by/4.0/. 
flowering plants, and abundant volatiles have been identified, including terpenoids, phenylpropanoids/benzenoids, and fatty acids in Osmanthus ${ }^{3}$, Dianthus ${ }^{4}$, Syr- $^{2}$ inga $^{5}$, Polianthes tuberos ${ }^{6}$, Ros $^{7}$, orchids ${ }^{8}$, freesia ${ }^{9}$, and Pelargonium $^{10}$. There is great variation in odor strength, even within one species, and plants have been divided into groups according to the sensory characteristics of their fragrance. Roses were the first flowers to be classified based on their scent compounds. There are seven recognized rose fragrances: rose, nasturtium, orris, violet, apple, lemon, and clove, according to Le Grice ${ }^{11,12}$, which has led to the breeding of modern roses for fragrance and contributed to the appeal of rose scents in flower markets ${ }^{13}$. Similar classification of flower aromas has also been conducted in other ornamental plants to encourage additional efforts to breed fragrant plants to increase their market value. Dianthus fragrances were divided into four groups based on their scent characteristics, medicinal fragrance, citrus-like, green leafy odor, and nonscented ${ }^{4}$ and tulip cultivars into nine groups: anise, citrus, fruity, green, herbal, herbal-honey, rosy, spicy, and woody ${ }^{13}$.

Lily, one of the world's best known ornamental plants, has a diversity of fragrance types, from weak scented to strong scented, which makes this flower a rich biochemical and genetic resource for aromas and flavors ${ }^{14}$. Nine different types of lilies have been classified by the Royal Horticultural Society according to parentage and flower shape: Asiatic hybrids (A); Martagon hybrids (M); European hybrids; American hybrids; Longiflorum hybrids (L); Trumpet and Aurelian hybrids (T); Oriental hybrids $(\mathrm{O})$; interdivisional hybrids; and all species, their varieties, and forms ${ }^{15}$. With the development of intersectional hybridization techniques, new interdivisional hybrid lily cultivars have been introduced, including LA (Longiflorum $\times$ Asiatic), OT (Oriental $\times$ Trumpet), and LO $\left(\right.$ Longiflorum $\times$ Oriental ${ }^{16}$. Over 60 volatile compounds have been identified from different lily cultivars ${ }^{14,17}$, and differences in the content and abundance of volatile molecules are believed to underlie the differences in lily fragrances ${ }^{14,18}$. Tepal tissues are major sources of floral scent compounds compared to the carpel and stamen ${ }^{14,17}$. Scent emissions occur in a circadian rhythm ${ }^{17}$ and function in nature to attract hawkmoths for pollination ${ }^{19}$. Lily volatiles that have been reported include terpenoids, benzenoids/phenylpropanoids, fatty acid derivatives, and nitrogen-containing and amino acid-derived compounds $^{14,17}$. Compared with scented lilies, the release of monoterpene compounds by nonscented lilies is either very low or undetectable ${ }^{17,18}$. Although basic information on lily floral scent compounds and emission patterns has been obtained in recent years, little is known about the classification of aroma types of Lilium. Such information would be useful for understanding the fragrance character of lilies and could be utilized for the selection and breeding of new varieties.

In most cases, floral scents are mixtures of many compounds, but there are always major compounds that contribute most significantly to typical scents. Benzyl acetate is the characteristic floral scent compound in Prunus mume ${ }^{20}$, phenylacetaldehyde in petunia "TX$794{ }^{21}$, benzenoids in carnation ${ }^{22}$, and monoterpenes in Lilium "Siberia"23. Monoterpenes are a class of terpenes that consist of two isoprene units synthesized mainly through the 2-C-methyl-D-erythritol-4-phosphate (MEP) pathway in the plastid ${ }^{24}$. Monoterpene synthase genes (monoTPSs) are key genes that encode enzymes that catalyze the last steps in the MEP pathway, converting geranyl diphosphate (GPP) into a range of monoterpenes $^{24,25}$ (Supplementary Fig. 1). To date, monoTPSs have been identified in many plants, including Thymus albicans $^{26}$, Camelina sativa ${ }^{27}$, and Alstroemeria ${ }^{28}$, and have been well described in Arabidopsis ${ }^{29,30}$ and Eucalyptus $^{30,31}$. TPS genes belong to a mid-sized gene family and range in number from 1 in Physcomitrella patens to 113 in Eucalyptus grandis ${ }^{30,32,33}$. An important characteristic of TPS enzymes is that they yield multiple products, depending on the substrate ${ }^{32,34}$. Steele et al. ${ }^{35}$ reported 52 different terpenes produced by one enzyme in Abies grandis, and at least 40 multisubstrate TPSs have been identified ${ }^{36}$.

Recently, two LiTPS genes have been cloned, one from Lilium "Siberia" (NCBI accession number KF734591), consisting of a 1761-bp open reading frame (ORF) and encoding a 587 amino acid protein ${ }^{37}$, and another, LhTPS cloned from "Belladonna" (NCBI accession number KR998333), with an ORF of 1758 bp corresponding to 586 amino acids ${ }^{14}$. However, no information is available on the genetic diversity of monoTPSs or their relationship to floral scent in lily. The objectives of this study were to (1) characterize floral volatile emissions in 41 lily accessions with different aroma types and produce a basic classification of aroma types in Lilium, (2) identify the nucleotide and haplotype diversity (Hd) for TPSs in a panel of 66 lily species/cultivars and evaluate its use for functional characterization, and (3) characterize the TPS gene transcripts from different lily accessions.

\section{Results}

Analysis and identification of novel floral scents from new Lilium hybrids and cultivars

Previous studies of lily fragrances have compared faintscented or strong-scented flowers from a few different lily types, including OT hybrids "Belladonna", "Conca D' Or", "Robina", and "Yelloween"; Oriental hybrids "Marco Polo", "Siberia", "Sorbonne", "Sunshine Borland", "Love story", "Pink Champion", "Santander", and "Tarrango"; Longiflorum hybrid "White Heaven"; Asiatic hybrids 
Table 1 Lily accessions used in this study

\begin{tabular}{|c|c|c|c|c|c|c|c|c|c|c|c|}
\hline No. & Type & Accession & No. & Type & Accession & No. & Type & Accession & No. & Type & Accession \\
\hline 1 & W & L. davidii var. unicolor Pinglu ${ }^{b}$ & 22 & A & L. tigrinum Splendens ${ }^{\mathrm{b}}$ & 43 & OT & Friso $^{b}$ & 64 & LA & Golden Stone $e^{a, b}$ \\
\hline 2 & W & L. davidii var. unicolor ${ }^{\mathrm{b}}$ & 23 & A & Discoteca $^{\mathrm{b}}$ & 44 & OT & Urandi $^{\mathrm{b}}$ & 65 & LA & Brindisi ${ }^{a, b}$ \\
\hline 3 & A & Easy Waltz ${ }^{\mathrm{b}}$ & 24 & $A$ & Levi $^{\mathrm{a}, \mathrm{b}}$ & 45 & OT & Conca D' Or ${ }^{\mathrm{a}, \mathrm{b}}$ & 66 & LA & Pavia $^{a}$ \\
\hline 4 & A & Little Kiss $^{b}$ & 25 & A & Elodie $^{\mathrm{a}, \mathrm{b}}$ & 46 & OT & Robina $^{\mathrm{b}}$ & 67 & LA & Surrender ${ }^{\mathrm{a}, \mathrm{b}}$ \\
\hline 5 & A & Easy life ${ }^{b}$ & 26 & A & Rosellas Dreamª, & 47 & OT & Olympic Torch ${ }^{\mathrm{b}}$ & 68 & LO & Triumphator ${ }^{\mathrm{a}, \mathrm{b}}$ \\
\hline 6 & $A$ & Peach Dwarf & 27 & A & Matrix ${ }^{\mathrm{b}}$ & 48 & OT & Yelloween ${ }^{b}$ & 69 & LO & White Triumphator ${ }^{a}$ \\
\hline 7 & $A$ & Red Twin ${ }^{\mathrm{b}}$ & 28 & A & Sunset Matrix ${ }^{\mathrm{b}}$ & 49 & OT & Amarossi $^{\mathrm{b}}$ & 70 & LO & Bell Song ${ }^{a}$ \\
\hline 8 & A & Ivory Pixie ${ }^{b}$ & 29 & A & Golden Matrix $^{\mathrm{b}}$ & 50 & OT & Outback $^{\mathrm{b}}$ & 71 & LO & Pink Brilliant ${ }^{a}$ \\
\hline 9 & A & Abbeville Pride $^{b}$ & 30 & $\mathrm{~T}$ & Pink Perfection ${ }^{a, b}$ & 51 & OT & Forever $^{\mathrm{b}}$ & 72 & LO & Pink Heaven ${ }^{a}$ \\
\hline 10 & A & Tailor Made ${ }^{b}$ & 31 & $\mathrm{~T}$ & Orange Planet ${ }^{\mathrm{a}, \mathrm{b}}$ & 52 & OT & Pink Mist ${ }^{\mathrm{a}, \mathrm{b}}$ & 73 & $\mathrm{~F}$ & Julius $^{\mathrm{b}}$ \\
\hline 11 & $A$ & Twosome & 32 & $\mathrm{~T}$ & Golden splendor $^{\mathrm{a}}$ & 53 & OT & Garden Affair ${ }^{\mathrm{a}}$ & 74 & $\mathrm{~L}$ & White Heaven ${ }^{a}$ \\
\hline 12 & A & Pink Pixie ${ }^{b}$ & 33 & T & Regale Album ${ }^{a}$ & 54 & ОТ & Palazzo ${ }^{a}$ & 75 & $\mathrm{O}$ & Mona Lisa ${ }^{b}$ \\
\hline 13 & A & Navona ${ }^{b}$ & 34 & $\mathrm{~T}$ & Regale $^{a}$ & 55 & OT & Manissa ${ }^{a}$ & 76 & $\mathrm{O}$ & Reeleeze $^{\mathrm{b}}$ \\
\hline 14 & A & Tiny Ghost ${ }^{b}$ & 35 & AT & Pearl Melanie & 56 & OT & Miss Feya ${ }^{a}$ & 77 & $\mathrm{O}$ & Entertainer $^{\mathrm{b}}$ \\
\hline 15 & $A$ & Tiny Invader ${ }^{b}$ & 36 & AT & Pearl Loraine $e^{a, b}$ & 57 & TO & Mister Right $t^{a, b}$ & 78 & $\mathrm{O}$ & After Eight ${ }^{b}$ \\
\hline 16 & A & Tiny Pearl ${ }^{b}$ & 37 & AT & Pearl Jessica ${ }^{a, b}$ & 58 & TO & Mister Sandman ${ }^{b}$ & 79 & O & Sorbonne $e^{a, b}$ \\
\hline 17 & A & Black Eye $e^{a, b}$ & 38 & AT & Red Velvet ${ }^{a, b}$ & 59 & TO & Leslie Woodriff & 80 & $\mathrm{O}$ & Siberia $^{\mathrm{b}}$ \\
\hline 18 & A & Pink Blossom ${ }^{b}$ & 39 & AT & Pink Flavour ${ }^{\mathrm{a}, \mathrm{b}}$ & 60 & TO & Mister Cass ${ }^{\mathrm{a}, \mathrm{b}}$ & 81 & $\mathrm{O}$ & White Dream ${ }^{b}$ \\
\hline 19 & $A$ & Annemaries Dream ${ }^{b}$ & 40 & AT & Red Life ${ }^{b}$ & 61 & TO & Beverly Dreams ${ }^{\mathrm{ab}}$ & 82 & $\mathrm{O}$ & Brasilia $^{a}$ \\
\hline 20 & A & Vermeer $^{\mathrm{b}}$ & 41 & TA & Night Rider ${ }^{a}$ & 62 & TO & Robert Swanson ${ }^{a}$ & 83 & LP & Fusion $^{a}$ \\
\hline 21 & A & Tiny Diamond $d^{\mathrm{a}, \mathrm{b}}$ & 42 & OT & Zambesi $^{b}$ & 63 & LA & Bright Diamond $d^{\mathrm{a}, \mathrm{b}}$ & 84 & $A L$ & Lady Alice ${ }^{a}$ \\
\hline
\end{tabular}

$W$ wild species, $A$ Asiatic hybrids, $T$ Trumpet hybrids, AT Asiatic $\times$ Trumpet hybrids, TA Trumpet $\times$ Asiatic hybrids, OT Oriental $\times$ Trumpet hybrids, TO Trumpet $\times$ Oriental hybrids, $L A$ Longiflorum $\times$ Asiatic hybrids, $L O$ Longiflorum $\times$ Oriental hybrid, O Oriental hybrids, $F$. formolongi, $L$ Longiflorum, $L P L$. longiflorum $\times L$. pardalinum, $A L$ Aurelian hybrids $\times$ Lilium henryi

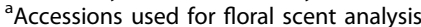

${ }^{\mathrm{b}}$ Cultivars used for total RNA extraction

"Tresor", "White Wizard", and "Red Wizard"; and LA hybrids "Music" and "Ceb Dazzle"14,17,18. In recent years, Trumpet hybrids, LO hybrids, and other new cultivars with distinct fragrances have become available. In this study, 41 cultivars of 12 different types (Table 1) were analyzed for volatile emissions, including 38 accessions that have not been investigated previously. A total of 46 individual volatile compounds were identified, ranging from 8 volatile components for "Pearl Melanie" to 34 components for "Regale album" (Supplementary Table 1). Of those components, 16 were identified for the first time in lilies, while the remainder had been identified in previous studies. Most newly identified compounds were either sesquiterpenes or derived from fatty acids (Supplementary Table 1).

\section{Grouping of lily cultivars based on their fragrance}

Each cultivar has a particular floral scent profile. There are 16 scent compounds that are considered major scent components and whose relative amounts are $>10 \%$ in some accessions, including 5 monoterpenoids ((E)- $\beta$-ocimene, myrcene, $\alpha$-pinene, eucalyptol, and linalool), 1 sesquiterpene (caryophyllene), 3 benzenoids (methyl benzoate, ethyl benzoate, and toluene), 1 phenylpropanoid-related (naphthalene), and 6 fatty acid-derived compounds (3-hexen-1-ol, methyl 2-methylbutyrate, methyl tiglate, methyl hexanoate, methyl octanoate, and 2-ethenyl-1,1dimethyl-3-methylenecyclohexane) (Supplementary Table 1). Methyl benzoate was the only component detected in all accessions. (E)- $\beta$-ocimene, naphthalene, and methyl 2methylbutyrate were detected in 39 accessions. Myrcene was also widely detected in 36 accessions (Supplementary Table 1).

Major scent compounds were classified into five groups (herbal, fruity, cool, floral, and spicy) based on their odor descriptions (Supplementary Table 2), and the scents of cultivars were classified into six groups based on the ratios of total amounts of scent compounds for each group (Table 2). 
Table 2 Classification of lily cultivars by their relative proportions of different scent compounds

\begin{tabular}{|c|c|c|c|c|c|c|}
\hline \multirow[t]{2}{*}{ Group } & \multirow[t]{2}{*}{ Cultivars } & \multicolumn{5}{|c|}{ Major scent compounds (\%) } \\
\hline & & Herbal & Fruity & Cool & Floral & Spicy \\
\hline \multirow[t]{14}{*}{ Faint scented } & Black Eye & 7.27 & 11.03 & 53.80 & 5.04 & 0.13 \\
\hline & Tiny Diamond & 13.3 & 33.77 & 6.39 & 23.22 & 0.3 \\
\hline & Levi & 12.61 & 52.39 & 12.15 & - & 1.11 \\
\hline & Elodie & 4.97 & 40.11 & 25.29 & - & 4.36 \\
\hline & Rosella's Dream & 6.93 & 22.51 & 5.23 & 10.77 & 22.27 \\
\hline & Pearl Melanie & - & 33.06 & 58.45 & - & - \\
\hline & Pearl Loraine & 12.04 & 43.05 & 15.95 & 5.79 & 5.43 \\
\hline & Pearl Jessica & 14.54 & 22.70 & 12.89 & - & 26.45 \\
\hline & Red Velvet & 1.37 & 58.57 & 12.06 & - & - \\
\hline & Lady Alice & 6.02 & 52.00 & 5.91 & - & 14.58 \\
\hline & Pink Flavour & 28.08 & 33.86 & 12.71 & - & - \\
\hline & Surrender & 37.28 & 31.65 & 0.27 & 13.78 & 1.96 \\
\hline & Fusion & 39.81 & 34.98 & 1.72 & 3.39 & - \\
\hline & Bright Diamond & 26.04 & 57.40 & 0.74 & 6.03 & 0.03 \\
\hline \multirow[t]{4}{*}{$\mathrm{Cool}$} & Robert Swanson & 9.36 & 1.49 & 66.30 & 1.77 & 0.18 \\
\hline & Beverly Dreams & 9.83 & 6.87 & 55.13 & - & 2.85 \\
\hline & Mister Right & 11.71 & 8.89 & 41.88 & - & 0.34 \\
\hline & Mister Cass & 16.30 & 4.86 & 57.22 & 4.60 & 0.23 \\
\hline \multirow[t]{4}{*}{ Fruity scent } & White heaven & 6.11 & 65.61 & 0.47 & 16.12 & - \\
\hline & Golden Stone & 4.47 & 69.35 & 0.22 & 13.38 & - \\
\hline & Brindisi & 3.21 & 87.69 & 2.21 & 1.72 & 0.33 \\
\hline & Pavia & 3.74 & 57.63 & 0.55 & 33.67 & 0.56 \\
\hline \multirow[t]{7}{*}{ Musky scent } & Pink Perfection & 4.38 & 68.71 & 21.67 & - & - \\
\hline & Regale & 5.87 & 34.72 & 20.94 & 2.33 & - \\
\hline & Golden Splendor & 6.14 & 60.15 & 29.8 & - & - \\
\hline & Night Rider & 6.95 & 44.75 & 31.93 & - & 2.32 \\
\hline & Regale Album & 7.64 & 40.40 & 22.83 & 1.18 & 0.02 \\
\hline & Manissa & 15.89 & 34.21 & 13.04 & 23.32 & - \\
\hline & Orange Planet & 20.45 & 9.71 & 60.56 & - & - \\
\hline \multirow[t]{9}{*}{ Fruity-honey scent } & White Triumphator & 1.38 & 81.75 & 0.12 & - & - \\
\hline & Garden Affair & 4.28 & 52.30 & 14.75 & - & - \\
\hline & Triumphator & 5.21 & 76.60 & 0.25 & 2.82 & - \\
\hline & Bell Song & 10.96 & 48.53 & 0.15 & 23.77 & - \\
\hline & Pink Heaven & 11.07 & 43.79 & 0.06 & 35.41 & - \\
\hline & Pink Brilliant & 14.64 & 20.37 & 1.82 & 59.28 & - \\
\hline & Conca D' Or & 11.24 & 63.77 & 6.12 & 9.93 & - \\
\hline & Pink Mist & 13.65 & 62.43 & 14.19 & - & - \\
\hline & Palazzo & 16.54 & 46.90 & 18.37 & 12.22 & - \\
\hline \multirow[t]{3}{*}{ Lily scent } & Miss Feya & 23.63 & 51.15 & 0.50 & 9.20 & 0.12 \\
\hline & Sorbonne & 33.42 & 36.78 & - & 4.43 & - \\
\hline & Brasilia & 34.72 & 45.00 & 0.19 & 6.43 & 0.01 \\
\hline
\end{tabular}

\section{Group 1, Faint scented}

Group 1, which had hardly any scent, comprised 14 cultivars, mainly belonging to Asiatic hybrids and AT hybrids. Although some important scent compounds such as linalool and methyl benzoate were detected in some cultivars (e.g., "Tiny Diamond”, "Levi”, "Rossella's Dream”, and "Pearl Loraine"), most humans are unable to detect any fragrance from these flowers by nose, although a few subjects in this study were able to detect a faint fragrance from flowers of "Pink Flavour", "Lady Alice", "Surrender", "Fusion", and "Bright Diamond", which had relatively high levels of methyl benzoate and (E)- $\beta$-ocimene.

\section{Group 2, Cool}

Group 2 had a weak scent with a cooling nuance and contained four cultivars, "Robert Swanson", "Beverly Dreams", "Mister Right", and "Mister Cass". All of these cultivars, which are TO hybrids, emitted a high 
percentage of eucalyptol and exhibited notable morphological characteristics, with dark green leaves and crooked stems, especially in young plants.

\section{Group 3, Fruity}

Group 3, consisting of "White Heaven", "Golden Stone", "Brindisi", and "Pavia", had a light fresh fruit odor, and methyl benzoate was the major scent compound. "White Heaven" is a Longiflorum hybrid, and the other three cultivars are LA hybrids. Compared to the other cultivars, "Pavia" had a high level of linalool in addition to methyl benzoate, which produced a fresh fruit scent with a floral note.

\section{Group 4, Musky}

Group 4 comprised of seven cultivars, five Trumpet hybrids ("Pink Perfection", "Orange Planet", "Golden Splendor", "Regale Album", "Regale"), one TA hybrid ("Night Rider"), and one OT hybrid ("Manissa"). All of those cultivars had a musky odor derived from high levels of eucalyptol and methyl benzoate, which many people find distasteful, especially in a confined space.

\section{Group 5, Fruity-honey}

Nine cultivars belonging to the OT and LO hybrids had fruity-honey odors with relatively high levels of methyl benzoate. "Triumphator" and "White Triumphator" had relatively high levels of methyl 2-methylbutyrate in addition to high levels of methyl benzoate, contributing a fruity and sweet odor. "Bell Song", "Pink Brilliant", and "Pink Heaven" had methyl benzoate and linalool as the major scent compounds, in addition to (E)- $\beta$-ocimene and myrcene. Linalool has a typical pleasant floral odor, $(\mathrm{E})-\beta$ ocimene and myrcene (ocimene-type) have herbaceous odors, and the three cultivars thus smelled fruity and sweet with a floral note. "Conca D' Or", "Pink Mist", "Garden Affair", and "Palazzo" emitted methyl benzoate in addition to eucalyptol and ocimene-type as the major scent compounds, generating a fruity odor with a sweet resinous nuance.

\section{Group 6, Lily}

Group 6 contained "Miss Feya" (OT hybrid) and "Sorbonne" and "Brasilla" (Oriental hybrids), which had high levels of ocimene-type and methyl benzoate, producing a strong fragrance with a cananga odor. This scent is very popular and was designated "lily", being so reminiscent of odors from cut Oriental hybrid lily flowers.

\section{Sequence alignment of TPS genes from different lily cultivars}

Methyl benzoate might be important for the formation of lily fragrance since it was detected in all lily accessions. However, monoterpenes were predicted to be the main contributors to the difference in floral scent between scented and faint-scented lilies ${ }^{23}$. As shown in Supplementary Table 1, monoterpenes occur frequently in lilies but in different relative amounts. They are also present in some cultivars that are normally considered faint scented. Monoterpenes are known to be synthesized mainly by the MEP pathway ${ }^{36}$, and monoTPSs encode the enzymes catalyzing the final steps of the MEP pathway. We tested the hypothesis that it was possible to identify polymorphic sites in lily flower-expressed monoTPSs related to the production of monoterpenes.

Thirty-two monoTPS cDNAs with high similarity were identified and sequenced from 66 lily accessions, and the sequences were submitted to NCBI (Table 3). The cDNAs were divided into three groups: LTPS-1, LTPS-2, and LTPS-3 (Fig. 1). LTPS-1 included the largest number of cDNAs (23 cDNAs in total) characterized by an ORF of 1761 bp encoding a putative LTPS protein of 586 amino acids. LTPS-3 included 7 cDNAs, with $97.71 \%$ homology to the LTPS-1 group, characterized by an ORF of $1647 \mathrm{bp}$ encoding a putative LTPS protein of 548 amino acids. There were only two cDNAs belonging to LTPS-2, with $98.59 \%$ and $94.44 \%$ homology to LTPS-1 and LTPS-3, respectively. The ORF of LTPS-2 is $1773 \mathrm{bp}$ and encodes a putative LTPS protein of 590 amino acids.

Table 3 shows the distribution of three types of terpene synthase transcripts, LTPS-1, LTPS-2, and LTPS-2, found in different lily cultivars examined in this study. LTPS-1 was found in $52(78.8 \%)$ lily cultivars. LTPS-3 was cloned from 18 cultivars, accounting for 27.3\%, and 6 (9.1\%) cultivars contained LTPS-2. "Sorbonne" was the only cultivar from which three types of LTPS were cloned. "Julius" was the only cultivar from which both LTPS-1 and LTPS-2 were cloned. LTPS-1 and LTPS-3 were cloned from seven cultivars, "Easy Life", "Abbeville Pride", "Red Life", "Reeleeze", "Pink Perfection", "Amarossi", and "Forever". Ten cultivars had only LTPS-3, and four cultivars (“Annemarie's Dream" “Orange Planet" "Conca D' Or" and "Bright Diamond") had only LTPS-2.

\section{Nucleotide diversity of LTPS-1, LTPS-2, LTPS-3, and haplotypes}

Sequence alignment of the 32 monoTPS sequences from lily showed 2 InDel polymorphisms $(230,873)$ and 64 single-nucleotide polymorphisms (SNPs). Compared to LTPS-1, 12 base pairs were inserted in LTPS-2 (230), and 114 base pairs were deleted in LTPS-3 (873). Of the 64 SNPs, 25 were synonymous mutations, while the other 39 altered the amino acid sequences (Supplementary Table 3).

Fifty-five, 8, and 41 SNP sites were identified for LTPS-1, LTPS-2, and LTPS-3, respectively, of which 33, 6, and 17 were nonsynonymous substitutions. Nucleotide diversity 
Table 3 Distribution of LTPS-1, LTPS-2, and LTPS-3 in 66 lily cultivars

\begin{tabular}{|c|c|c|c|}
\hline Group & Material & Gene name & Accession no. \\
\hline \multirow[t]{23}{*}{ LTPS-1 } & 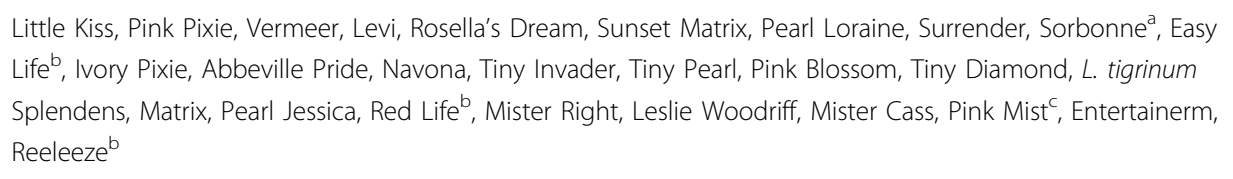 & LIkTPS-1 & MH203231 \\
\hline & Easy Waltz, Red Velvet, Pink Perfection ${ }^{\mathrm{b}}$ & LewTPS-1 & MH2O3230 \\
\hline & Tailor Made & LtmTPS-1 & MH203236 \\
\hline & Tiny Ghost & LtgTPS-1 & MH203239 \\
\hline & L. davidii var. unicolor "Pinglu" & LpluTPS-1 & MH203273 \\
\hline & Lilium davidii var. unicolor & LIZTPS-1 & MH203274 \\
\hline & Pearl Melanie & LpemTPS-1 & MH203268 \\
\hline & Mona Lisa & Lm/TPS-1 & MH203251 \\
\hline & Olympic Torch, Yelloween, Outback & LyeTPS-1 & MH203282 \\
\hline & Pink Mist ${ }^{c}$ & LpimTPS2-1 & MH203288 \\
\hline & After Eight & LaeTPS-1 & MH203279 \\
\hline & Peach Dwarf & LpdTPS-1 & MH203233 \\
\hline & Black Eye & LbeTPS-1 & MH203242 \\
\hline & Zambesi & LzaTPS-1 & MH203255 \\
\hline & Friso & LfrTPS-1 & MH203256 \\
\hline & Urandi & LURTPS-1 & MH203257 \\
\hline & Robina & LroTPS-1 & MH203258 \\
\hline & Mister Sandman & LmsTPS-1 & MH203265 \\
\hline & Golden Stone & LgsTPS-1 & MH203261 \\
\hline & Amarossi $^{b}$ & LamTPS-1 & MH203283 \\
\hline & Forever $^{\mathrm{b}}$ & LfOTPS-1 & MH203287 \\
\hline & Julius $^{d}$ & LjuTPS-1 & MH203263 \\
\hline & Siberia & LsiTPS-1 & $\mathrm{MH} 203254$ \\
\hline \multirow[t]{2}{*}{ LTPS-2 } & Sorbonne ${ }^{a}$, Julius ${ }^{d}$, Conca D’ Or, Orange Planet, Annemarie Dream & LsoTPS-2 & MH203303 \\
\hline & Bright Diamond & LbdiTPS-2 & MH203304 \\
\hline \multirow[t]{7}{*}{ LTPS-3 } & Easy life ${ }^{\mathrm{b}}$, Discoteca, Elodie, Pink Flavour, Red Life ${ }^{\mathrm{b}}$, Pink Perfection”, Triumphator, White Dream & LdiTPS-3 & MH203298 \\
\hline & Sorbonne ${ }^{a}$, Reeleeze ${ }^{b}$, Brindisi, Golden Matrix, Twosome & LSOTPS-3 & MH203275 \\
\hline & Red Twin & LrtTPS-3 & MH2O3295 \\
\hline & Abbeville Pride & LapTPS-3 & MH203296 \\
\hline & Amarossi $^{\mathrm{b}}$ & LamTPS-3 & MH203284 \\
\hline & Forever $^{\mathrm{b}}$ & LfOTPS-3 & MH203286 \\
\hline & Beverly Dreams & LbdrTPS-3 & MH203280 \\
\hline
\end{tabular}

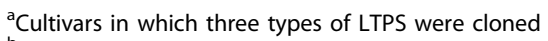

${ }^{b}$ Cultivars in which both LTPS-1 and LTPS-3 were cloned

${ }^{c}$ Cultivars in which two LTPS- 1 were cloned

${ }^{d}$ Cultivars in which both LTPS-1 and LTPS- 2 were cloned

$(\pi)$ was determined for LTPS-1, LTPS-2, and LTPS-3 $(\pi=0.010)$ than for LTPS-3 $(\pi=0.006)$ and LTPS-2 ORFs using the SNPs identified in the lily accessions. $(\pi=0.001)$. Hd was approximately 1.0 for the three Overall, nucleotide diversity was higher for LTPS-1 LTPS groups (Table 4). 


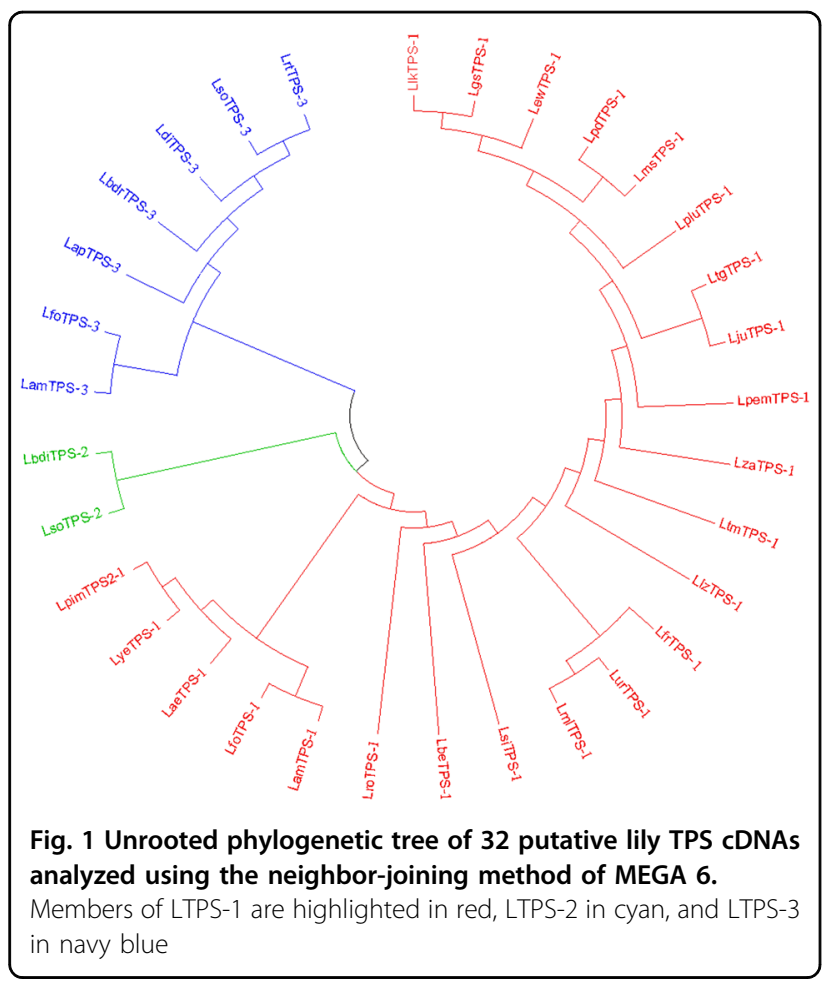

\section{Comparison of lily genomic DNA sequences and LTPS flower transcripts}

The cultivar "Sorbonne" was the only accession from which three types of LTPS were cloned, and it was chosen for DNA cloning to investigate the InDel relationships between LTPS-2 and LTPS-3 at the DNA level. A total length of $2661 \mathrm{bp}$ genomic LTPS DNA was cloned from "Sorbonne" (LsoTPS-gDNA, NCBI accession number MH618207) and aligned with the cDNAs of LsoTPS-1 (MH203231), LsoTPS-2 (MH203303), and LsoTPS-3 (MH203275) by the DNAMAN software. Seven exons and six introns were found for the LTPS genomic DNA. As shown in Fig. 2, the additional 12 bases of LsoTPS-2, which are not present in LsoTPS-1 and LsoTPS-3, are not actually due to an insertion in the DNA-coding sequence but rather arise from the use of an alternative $5^{\prime}$ splice site in the first intron. Furthermore, the 114 bases missing from LsoTPS-3 compared to LsoTPS-1 and LsoTPS-2 are not due to the deletion of any DNA sequence but rather arise from the use of an alternative $3^{\prime}$ splice site in the third intron. This suggests that the explanation for the presence of the LTPS-1, LTPS-2, and LTPS-3 transcripts might be variable splicing of transcripts from an LTPS gene.

\section{Correlation of scent compounds emitted and TPS gene nucleotide substitutions}

Fifty-one SNPs were identified among the cDNA sequences from the 23 cultivars from which floral scent components were identified. Gray relational analysis was used to evaluate the gray relational degree (GRD) between the major monoterpene volatile compounds emitted and the 51 TPS nucleotide substitutions ${ }^{38,39}$ using the DPS V12.01 software. The compound that had the highest correlation with all nucleotide substitution sites (GRD > 0.57) was myrcene (Fig. 3). The substitution site 230-241, which corresponds to the insertion of $12 \mathrm{bp}$, was highly correlated with all major monoterpene volatile compounds (GRD > 0.59), especially (E)- $\beta$-ocimene $(\mathrm{GRD}>$ 0.72) (Fig. 3).

\section{Characterization of LTPS-1, LTPS-2, and LTPS-3}

The translation of all LTPS cDNAs into amino sequences generated 14,7 , and 2 amino sequences for LTPS-1, LTPS-3, and LTPS-2, respectively. The amino acid sequences from "Sorbonne" lily LsoTPS-1, LsoTPS-2, and LsoTPS-3 were used for characterization of the encoded proteins. All three sequences contained the highly conserved N-terminal arginine-rich RRX8W signature sequence motif and the C-terminal aspartate-rich DDXXD and NSE/DTE substrate-binding motifs ${ }^{32}$, with a predicted mass of ca. $66.3 \mathrm{kDa}$ and a pI of ca. 5.8 (Fig. 4). The N-terminal 20 amino acids upstream of the conserved RRX8W motif were predicted to code for a transit peptide for import into plastids using the SignalP 4.1 peptide prediction tool. Although one highly conserved RX8W motif was found in the LsoTPS-1 and LsoTPS-2 amino sequences, a similar sequence was absent from the predicted LsoTPS-3 amino sequence (Fig. 4) because of the deletion produced by alternative splicing, as discussed above.

\section{Functional characterization of LTPS-1, LTPS-2, and LTPS-3}

To determine the functional activity of the three structurally distinct types of TPS proteins, five cDNAs were expressed separately in Escherichia coli. BL21, three from the scented lily Lilium cv. "Sorbonne" (LsoTPS-1, LsoTPS-2, and LsoTPS-3) and two from the faint-scented Lilium cv. "Red life" (LrlTPS-1, MH203231, and LrlTPS-3, MH203298). The recombinant plasmid with the fulllength LsoTPS-1, LsoTPS-2, and LsoTPS-3 cDNA sequences resulted in successful expression of soluble LsoTPS-1, LsoTPS-2, and LsoTPS-3 proteins of approximately 67,68 , and $62 \mathrm{kDa}$, respectively. The recombinant plasmid with the full-length LrlTPS-1 and LrlTPS-3 cDNAs resulted in successful expression of soluble proteins of approximately 67 and $62 \mathrm{kDa}$, respectively. Each of the purified proteins was tested for the ability to convert GPP into monoterpenes, and the products generated were analyzed by gas chromatograph-mass spectrometer (GC-MS). The results showed that all five proteins were able to convert GPP into (E)- $\beta$-ocimene, $\alpha$-pinene, and limonene, which were identified by retention time at 5.79 , 
Table 4 Nucleotide diversity of LTPS-1, LTPS-2, and LTPS-3 in the lily accessions

\begin{tabular}{llllll}
\hline Group & SNP site & Nonsynonymous substitution & Nucleotide diversity $(\boldsymbol{\pi})$ & No. of haplotypes & Haplotype diversity (Hd) \\
\hline LTPS-1 & 55 & 33 & 0.010 & 23 & 0.99 \\
LTPS-2 & 8 & 6 & 0.001 & 2 & 1.00 \\
LTPS-3 & 41 & 17 & 0.006 & 7 & 1.00 \\
\hline
\end{tabular}

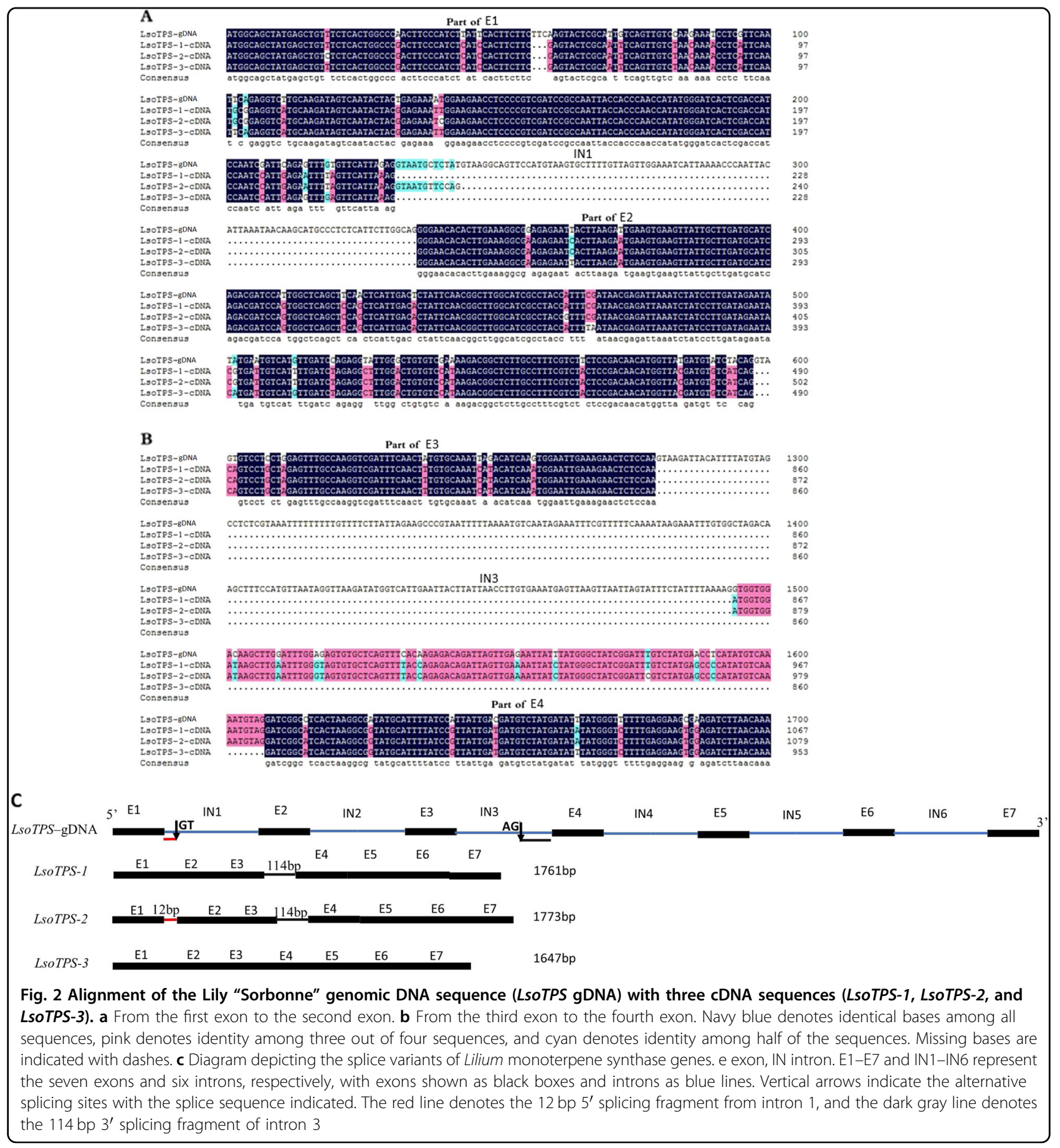


5.56, and $5.47 \mathrm{~min}$, respectively (Fig. 5 shows the results for LrlTPS-3 as an example). As shown in Fig. 5, even if the transformed $E$. coli cells were cultivated in buffer without isopropyl- $\beta$-D-thiogalactoside (IPTG) and substrate (GPP), a small amount of eucalyptol was produced, as identified by retention time at $5.58 \mathrm{~min}$.

\section{Discussion}

\section{Complexity and diverse nature of lily floral aroma compounds}

Mixtures of volatile compounds are responsible for the varied fragrances of flowers and fruits. In this study, a diverse range of lily accessions was used for the analysis of floral volatiles and terpene synthase genes, including the largest lilies, new cultivars and hybrids, and scented and faint-scented types. A total of 46 volatile compounds were

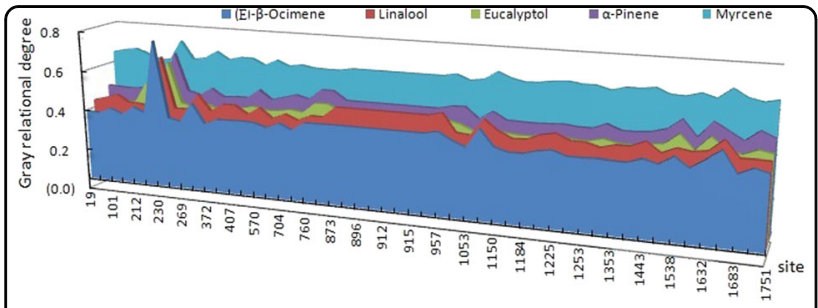

Fig. 3 Gray relational analysis between monoterpene volatile compounds and TPS nucleotide substitutions using the DPS software identified from 41 lily accessions, including 16 reported for the first time in lily (Supplementary Table 1). The observed differences between the volatiles reported here and the figures given by other authors ${ }^{14,17,18}$ can be explained either by the different flower scent collection methods employed or the different lily accessions investigated. Monoterpene hydrocarbons, monoterpene alcohols and aldehydes, phenylpropanoids, benzenoids, and fatty acid derivatives were the major chemical classes found (Supplementary Table 1).

Although it has been reported that monoterpenoids and benzenoids are the major compounds emitted from scented lily flowers ${ }^{14,17}$, volatiles such as eucalyptol, linalool, and benzenoids were also identified in some faint-scented lilies in this research. The level of gene expression might influence the production of important volatile organic compounds, but it is also possible that volatile compounds can be synthesized in some faintscented lilies; however, obstacles in the secretary pathway may prohibit their emission in amounts that are sufficient for aroma generation. It is well known that floral scent compounds are produced in a number of diverse secretory compartments, including nectaries, glandular trichomes, eliaphores, osmophores ${ }^{40,41}$, and tepals, which are the source of lily floral scent ${ }^{14,17}$. So far, little is known in lilies or other flowers about the intracellular biosynthesis of volatile compounds in secretary cells and the trafficking of these compounds from their sites of synthesis to their

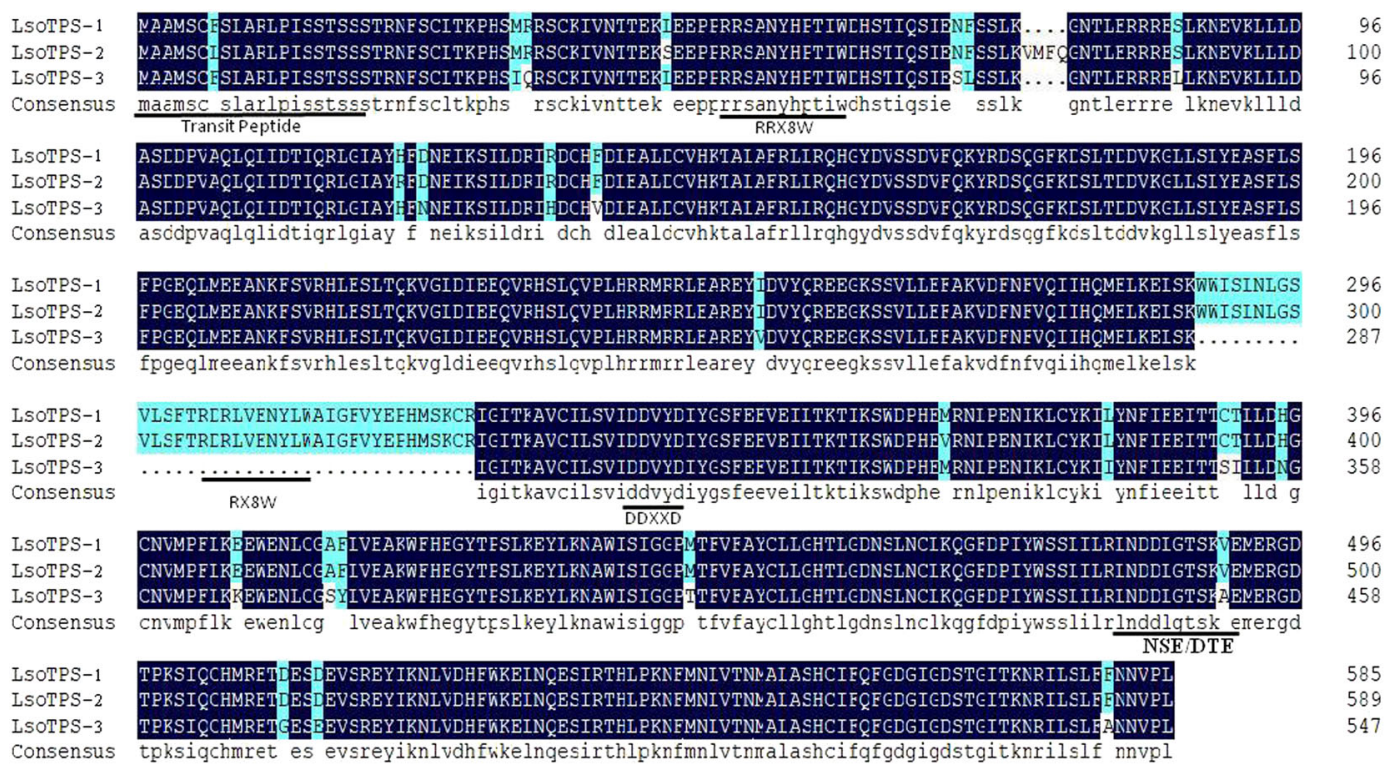

Fig. 4 Alignment of the deduced amino acid sequences of LsoTPS-1, LsoTPS-2, and LsoTPS-3. The N-terminal transit peptide and conserved amino acid motifs RRX8W, RX8W (missing in LsoTPS-3 due to the alternative splicing), DDXXD, and NSE/DTE are indicated. RRX8W has been suggested to facilitate the isomerization-cyclization reaction ${ }^{10}$. DDXXD and NSE/DTE are speculated to form the binding site for the substrate (GPP)-divalent metal cation $\left(\mathrm{Mg}^{2+}, \mathrm{Mn}^{2+} \text {, etc. }\right)^{32}$. RX8W is speculated to be the substrate-binding pocket according to an NCBI CD search (https:// www.ncbi.nlm.nih.gov/Structure/cdd/wrpsb.cgi?tdsourcetag) 


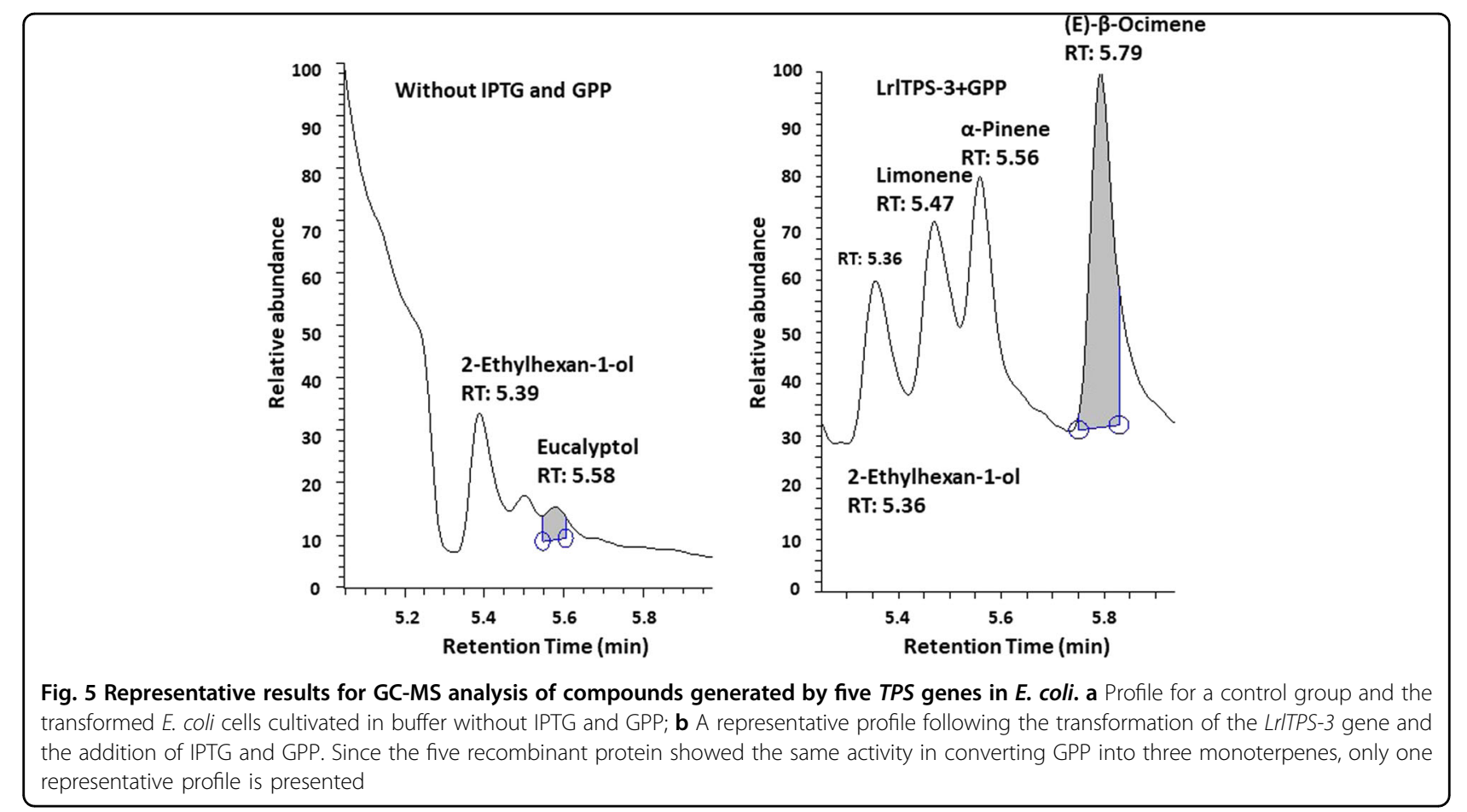

sites of emission ${ }^{42-44}$. Those faint-scented lilies, such as "Black Eye" and "Pearl Melanie" (Table 2 and Supplementary Table 1), that emitted faint characteristic flower scent compounds would be suitable materials for further research on factors that limit the transportation of volatile organic components to sites where they can be emitted.

Classification of aroma types is challenging, and in many cases, it is difficult for the human nose to characterize the sensual features of a flower. The development of sensitive analytical methods, such as solid-phase microextraction (SPME), headspace adsorption, and GCMS, has made it easier to collect and analyze volatile compounds, and these methods have been applied to research the aromas of liquor ${ }^{45}$, tobacco ${ }^{46}$, fruits such as strawberry ${ }^{47}$ and grape ${ }^{48}$, and flowers such as rose ${ }^{49}$ and tulip $^{13}$. In most cases, flower aroma levels have been described simply as nonscented, light scented, and strong scented $^{17}$. A more sophisticated method of classification by scent quality previously used for tulip cultivars ${ }^{13}$ was introduced in this study, and 41 lily cultivars were classified into six groups according to the composition of major scent components: Group 1, faint scented; Group 2, cool; Group 3, fruity; Group 4, musky; Group 5, fruityhoney; and Group 6, lily (Table 2). To our knowledge, this is the first time that lily cultivars have been classified by scent quality, and this precision may encourage successful efforts to breed fragrant lilies.

\section{Correlation between the nucleotide diversity of lily} monoTPSs and the production of volatile compounds

Monoterpenes are major volatile constituents of many plants, such as rose ${ }^{7}$, grapevine ${ }^{48}$, and strawberry guava ${ }^{50}$. Nucleotide diversity is closely related to phenotypic polymorphism and has been applied in association studies $^{51}$ and for haplotype mapping ${ }^{52}$ and linkage disequilibrium $^{53}$. In this study, 32 candidate monoTPS cDNAs were obtained from 66 lily cultivars, and two InDels and 64 SNPs were identified. The nucleotide diversity for LTPS ranged from 0.001 (for LTPS-2) to 0.010 (for LTPS-1) (Table 4). Nucleotide diversity differs with species, cultivars, and genes. In an investigation of the nucleotide diversity of 11 frost-tolerance genes in five winter rye populations, $\pi$ ranged from 0.004 to $0.0145^{53}$ and $\pi$ was 0.00834 for $O$-methyltransferase genes in 42 maize inbred lines ${ }^{54}$.

As a mid-sized gene family, plant TPSs have been subclassified into seven subfamilies ${ }^{55,56}$. MonoTPSs belong to subfamilies TPS-b, TPS-g, and TPS-e/ $\mathrm{f}^{33,36}$, and the size of the monoTPS gene family mirrors the complexity of monoterpene emissions from different plants. Phylogenetic analysis showed that the 32 candidate monoTPS cDNAs in lilies identified in the present study all belonged to the TPS-b subfamily (Supplementary Fig. 2). LTPS-1 presented the highest levels of nucleotide diversity in this study, and a total of 23 LTPS-1 were identified from $78.8 \%$ of lily cultivars, including the 
Asiatic hybrid "Little Kiss" (faint scented), Oriental hybrid "Sorbonne" (lily scent), OT hybrid "Pink Mist" (fruityhoney scent), Trumpet hybrid "Pink Perfection" (musky scent), and LA hybrid "Golden Stone" (fruity scent) (Tables 1-3). The two TPS sequences reported from the typical lily-scented "Siberia" and "Belladonna" by Zhang et al. ${ }^{37}$ and Johnson et al. ${ }^{14}$ are members of subfamily TPS-b and were similar/identical to TPS-1 in our study (Supplementary Fig. 2). Recently, Abbas et al. ${ }^{57}$ reported LoTPS3 from "Siberia" belonging to the TPS-g family.

In lily, all identified nucleotide substitution sites were highly related to the amounts of myrcene emitted (Fig. 3), which varied from $0 \%$ to $14.67 \%$ in different lily accessions (Supplementary Table 1). InDel site 230 was found to be highly correlated with all emissions of major monoterpenoid components, especially (E)- $\beta$-ocimene (Fig. 3), which indicates the potential importance of this site for determining the production of monoterpenes. Unfortunately, the volatile compounds from lilies comprise such a complex mixture of aroma types (herbal, cool, fruity, etc.) present in different concentrations, with each volatile compound having its own threshold values (Supplementary Table 2), that the differences in (E)- $\beta$-ocimene and myrcene observed in this study cannot be linearly related to the differences in aroma. The alignment of genomic DNA sequences with those obtained from LTPS transcripts led to the discovery of variable splicing (Fig. 2), which indicates that the variation in emission might be regulated at the posttranscriptional level, as has been suggested previously for other plants ${ }^{58}$. It is well established that nearly all splice sites conform to consensus sequences with GT at the $5^{\prime}$ end of the intron and AG at the $3^{\prime}$ end of the intron ${ }^{59}$. These sequences were found at the alternative splice sites in this study and are indicated in Fig. 2c. The functional significance of this alternative splicing needs to be directly tested, however.

\section{MonoTPSs in lily encode multifunctional enzymes}

Plant terpene synthases share a common evolutionary origin based on their similar reaction mechanisms and conserved structural and sequence characteristics ${ }^{60}$. All angiosperm monoterpene synthase genes contain six introns and seven exons ${ }^{36,60}$, and the TPS protein family is characterized by three domains: the N-terminal RRX8W motif and C-terminal DDXXD and NSE/DTE motifs ${ }^{61}$. Yueh-Te cloned three monoterpene synthase genes from Litsea cubeba that converted GPP into different products $^{55}$. Shimada isolated four cDNA clones for monoterpene synthase genes from Satsuma mandarin, and each one encoded a different synthase ${ }^{62}$. In most lilies, however, only one monoTPS cDNA was cloned, although in the present study, two types of monoTPS cDNAs were cloned in eight lilies and three in "Sorbonne" (Table 3). The genomic TPS DNA cloned from "Sorbonne" lily contained seven exons and six introns, and the three conserved domains, RRX8W, DDXXD, and NSE/DTE, were also identified in the putative LTPS amino acid sequence (Figs. 2 and 4). Presumably, the cDNAs cloned in this study were from the same ancestral monoterpene synthase genes possessing the ability to catalyze the isomerization-cyclization reaction (RRX8W) and metal cofactor binding (DDXXD and NSE/DTE) ${ }^{63}$. The results of functional characterization experiments indicated that the enzymes encoded by monoTPS cDNAs from lilyscented "Sorbonne" and faint-scented "Red Life" could all catalyze the conversion of GPP into monoterpenes, which suggests that monoterpene production may be limited by substrate availability or transport in faint-scented flower types.

The striking feature of TPS enzymes is that a single TPS enzyme using a single substrate often gives rise to multiple products ${ }^{32,34}$. However, here, we showed that recombinant plasmids constructed from five cDNAs cloned from both faint- and strong-scented lilies were all multifunctional monoTPS that could convert GPP to (E)$\beta$-ocimene, $\alpha$-pinene, and limonene (Fig. 5). It has been reported that (E)- $\beta$-ocimene synthase in snapdragon produced three monoterpenes ${ }^{64}$. The protein encoded by At3g25820/At3g25830 from Arabidopsis catalyzed the formation of ten volatile monoterpenes from GPP, as reported by Chen et al. ${ }^{65}$. It has been suggested that the formation of multiple products might be enhanced by the NSE/DTE motif ${ }^{34}$. However, the LsoTPS-3 and LrlTPS-3 forms both have catalytic activity in E. coli, but both lack the conserved RX8W motif, which suggests that this sequence is not essential for enzyme function or production of multiple products.

It is well known that monoterpene synthases have an $\mathrm{N}$ terminal signal peptide that targets the initial translation product to the plastids ${ }^{34,66}$. Although several studies have highlighted interactions between plastidial MEP and cytosolic mevalonate pathways ${ }^{10,67}$, the occurrence of a predicted transit peptide indicates that monoterpenoids in Lilium might all be produced by the MEP pathway in plastids. Often, signal peptides are removed before TPS transcripts are expressed in E. coli ${ }^{55}$, but this did not occur in this study, which might explain why all TPSs in this study showed low catalytic activities when heterologously expressed (Fig. 5). The emission profiles from lily shown in Table 1 do not relate well to the emission measured after heterologous expression of the TPS genes in E. coli, and a comparison should be made of the catalytic activities with and without transit peptides. The emission results were obtained with 41 lilies of different aroma types, while TPSs from only two lilies were tested. In the latter case, the principal scent compounds in Table 2 , apart from (E)- $\beta$-ocimene, did not correspond directly to the principal scent compounds produced during 
heterologous expression. More precise functional identification of alternatively spliced transcripts and their products will be the subject of a separate study.

In summary, we analyzed volatile emissions from 41 cultivars and performed a classification of flower aroma types of Lilium. In addition, we identified Lilium monoTPS polymorphisms and alternative splicing products and confirmed the catalytic activity of the encoded protein products. The findings in this study provide a major resource for the assessment of lily scent volatiles and will be helpful for the selection of breeding materials based on the volatile components they produce.

\section{Materials and methods Plant materials}

Eighty-four Lilium accessions were planted in an open field at the Horticultural Station of Shanxi Agricultural University, Taigu, Shanxi, China on March 25, 2017, including 2 species (W), 27 Asiatic hybrids (A), 5 Trumpet hybrids (T), 6 Asiatic $\times$ Trumpet hybrids (AT), 1 Trumpet $\times$ Asiatic (TA), 15 Oriental $\times$ Trumpet hybrids $(\mathrm{OT})$, 6 Trumpet $\times$ Oriental hybrids (TO), 5 Longiflorum $\times$ Asiatic hybrids (LA), 5 Longiflorum $\times$ Oriental hybrids (LO), 8 Oriental hybrids (O), 1 L. formolongi hybrid (F), 1 Longiflorum hybrid (L), 1 Lilium longiflorum $\times$ L. pardalinum hybrid (LP), and 1 Aurelian $\times$ Lilium henryi hybrid (AL) (Table 1). Petals were collected at the full flowering stage, frozen in liquid nitrogen, and stored at $-80^{\circ} \mathrm{C}$ for RNA extraction.

\section{Floral scent collection and analysis}

Flowers of the 41 accessions listed in Table 1 were harvested at the full flowering stage from 8:00 to 10:00 a. $\mathrm{m}$. on a sunny day from June to July 2018 for floral scent collection. Four or five accessions were selected from types for which there were more than five accessions. Triplicate samples were brought directly into the laboratory and used for sensory assessment and headspace volatile analysis. Volatile emission collections were conducted using the immersion SPME method ${ }^{3}$. Fresh flower samples $(1.5 \mathrm{~g})$ were placed in a $15 \mathrm{~mL}$ SPME vial, and 3heptanone (Dr. Ehrensorfer Company with Limited Liability) was added as an internal standard. A preconditioned SPME fiber $(50 / 30 \mu \mathrm{m}$ PDMS/DVB/CAR, Supelco) was then exposed to the headspace of the capped vial at $50{ }^{\circ} \mathrm{C}$ for $15 \mathrm{~min}$. The fiber was injected automatically and desorbed in the injection chamber of the GC in splitless mode for $5 \mathrm{~min}$ at $270^{\circ} \mathrm{C}$.

Quantification of volatiles was carried out using a GCMS in the Sharing Platform of the Experimental Teaching Center of Shanxi Agricultural University. The GC (Trace ISQ, Thermo Scientific) was equipped with a capillary DB-5MS column $(30 \mathrm{~m} \times 0.25 \mathrm{~mm}$ inner diameter (i.d.) with $0.25-\mu \mathrm{m}$ film thickness). Helium was used as the carrier gas, and the flow rate was $1 \mathrm{~mL} / \mathrm{min}$. The GC oven temperature was programmed at $40^{\circ} \mathrm{C}$ for $2 \mathrm{~min}$, increased from 40 to $270{ }^{\circ} \mathrm{C}$ at a rate of $5^{\circ} \mathrm{C} / \mathrm{min}$, and then held for $5 \mathrm{~min}$. The mass spectra (Trace ISQ, Thermo Scientific) were taken at electron ionization at $70 \mathrm{eV}$, and the mass range was $45-600 \mathrm{~m} / \mathrm{z}$. Both the ion source temperature and the transfer line temperature were $280^{\circ} \mathrm{C}$. Compounds were identified by matching to data from the NIST08 library in the Xcalibur software. Peak areas were normalized as a percentage and used to determine the amounts of the volatiles as described ${ }^{68}$ : content of each component $(\mu \mathrm{g} / \mathrm{g})=[($ peak area of each component $\times$ content of internal standard)/peak area of internal standard]/sample weight.

\section{Classification of scents}

Odor description terms of fresh flowers were mainly derived by referring to Burdock ${ }^{69}$ and Oyama-Okubo ${ }^{13}$.

\section{RNA and DNA extraction and first-strand CDNA synthesis}

The total RNA of a mixture of petals from the 66 lily cultivars in Table 1 was extracted following the TriGene reagent (GenStar) protocol. DNA from "Sorbonne" was isolated from young leaves using the CTAB method ${ }^{70}$. The quality and quantity of total RNA and genomic DNA were examined using a NanoDrop 2000C spectrophotometer (Thermo Scientific). First-strand cDNA was synthesized using the StarScript II First-Strand cDNA Synthesis Kit (GenStar) according to the manufacturer's instructions and diluted to $100 \mathrm{ng} / \mu \mathrm{L}$. The purified DNA samples were diluted to $20 \mathrm{ng} / \mu \mathrm{L}$.

\section{Isolation of full-length Lilium monoTPS CDNA and genomic DNA}

Cloning primers were designed based on the sequence of LsTPS (NCBI accession: MF401556) using Primer 3.0 (http://bioinfo.ut.ee/primer3-0.4.0/primer3/). Primer pairs (5'-ATGGCAGCTATGAGCTGT-3'/5'-TCATTC-

CAATGGGACATTATTG-3') were synthesized by Sangon Biotech (Shanghai) Co., Ltd. PCRs were performed in $50 \mu \mathrm{L}$ volumes: $2 \mu \mathrm{L}$ of cDNA or DNA, $0.5 \mu \mathrm{L}$ of each primer, $5 \mu \mathrm{L}$ of $10 \times$ TransTaq $^{\circledR}-\mathrm{T}$ Buffer, $4 \mu \mathrm{L}$ of $2.5 \mathrm{mM}$ dNTPs, $1 \mu \mathrm{L}$ of TransTaq ${ }^{\oplus}-\mathrm{T}$ DNA Polymerase, and $37 \mu \mathrm{L}$ of $\mathrm{ddH}_{2} \mathrm{O}$. The cycling conditions were as follows: $95^{\circ} \mathrm{C}$ for 5 min, followed by 35 cycles of $95^{\circ} \mathrm{C}$ for $30 \mathrm{~s}, 55^{\circ} \mathrm{C}$ for $30 \mathrm{~s}$, and $72^{\circ} \mathrm{C}$ for $1 \mathrm{~min}$. The final extension step was followed by incubation for $10 \mathrm{~min}$ at $72{ }^{\circ} \mathrm{C}$. Gel extraction and purification of amplicons were carried out using a TIANgel Midi purification Kit (Tiangen Biotech). Each independent amplicon was ligated into the PMD-19T vector $(\mathrm{TaKaRa})$ and then sequentially transformed into Trans $5 \alpha$ chemically competent cells (TransGen Biotech). Sequencing was performed with three replicates by Sangon Biotech. 


\section{Heterologous expression of monoterpene synthases}

Restriction sites and protective bases were added to the $5^{\prime}$ end of the primer $\left(5^{\prime}\right.$-CGGACTAGTATGGCAGCTATG AGCTGT-3'/5'-CCGCTCGAGTCATTCCAATGGGACA TTATTG-3'). The cloning process was the same as described above. Monoterpene synthase genes from lilyscented "Sorbonne" and faint-scented "Red life" were subcloned into the fusion protein expression vector PTYB12, and the resultant constructs were expressed in E. coli BL21 (DE3) with intact plastidial signal peptides. The transformed E. coli cells were cultured overnight at $37^{\circ} \mathrm{C}$ in Luria-Bertani medium and induced with $0.4 \mathrm{mM}$ IPTG at $16{ }^{\circ} \mathrm{C}$ for $20 \mathrm{~h}$. At the same time, the transformed E. coli cells were cultured overnight at $37^{\circ} \mathrm{C}$ in Luria-Bertani medium and cultivated without $0.4 \mathrm{mM}$ IPTG at $16^{\circ} \mathrm{C}$ for $20 \mathrm{~h}$ as the control group (CK).

\section{Monoterpene synthase activity assay}

The transformed E. coli cells were disrupted by a Bioruptor Plus sonication device. The product $(\mathrm{mL})$ was added to monoTPS buffer (10 mM HEPES, $\mathrm{pH}$ 7.2; $100 \mathrm{mM} \mathrm{KCl} ; 10 \mathrm{mM} \mathrm{MgCl} 2 ; 10 \%$ (v/v) glycerol; $5 \mathrm{mM}$ dithiothreitol) with $30 \mu \mathrm{M}$ GPP (SinoStandards). At the same time, the product from CK was added to monoTPS buffer without GPP. The reaction mixture was incubated at $30^{\circ} \mathrm{C}$ for $3 \mathrm{~h}$. The products produced by the assay were collected using the immersion SPME method mentioned above and analyzed, with 3-heptanone as an internal standard, using a GC-MS equipped with a DB-5 capillary column ( $30 \mathrm{~m}$ length, $0.25 \mathrm{~mm}$ i.d., $0.25 \mu \mathrm{m}$ film thickness). The oven temperature was held at $80^{\circ} \mathrm{C}$ for $1 \mathrm{~min}$, increased from $80^{\circ} \mathrm{C}$ to $200{ }^{\circ} \mathrm{C}$ at a rate of $4{ }^{\circ} \mathrm{C} / \mathrm{min}$, and then held for $5 \mathrm{~min}$. The injector temperature was $250^{\circ}$ $\mathrm{C}$; the ion source temperature was $280^{\circ} \mathrm{C}$; the EI was $70 \mathrm{eV}$; the carrier gas was $\mathrm{He}$ at a flow rate of $1 \mathrm{~mL} / \mathrm{min}$; the mode was splitless; and the mass range was $45-425 \mathrm{~m} / \mathrm{z}$.

\section{Sequence analysis}

Insertions, deletions, and SNP positions were assessed using DNAMAN 8. Hd of monoTPS was analyzed based on the SNPs in the amplified ORF sequences from 66 lily accessions. The levels of nucleotide diversity were estimated as $\pi$, the average number of nucleotide differences per site between two sequences ${ }^{53}$. Hd was estimated as the probability that two randomly chosen haplotypes from the 66 accessions were different ${ }^{51,53}$. Conserved domains in the protein were determined using NCBI Conserved Domains (http://www.ncbi.nlm.nih.gov/Structure/cdd/wrpsb.cgi).

The phylogenetic trees were constructed using MEGA 6, and the bootstrap replication was 1000. SignalP 4.1 was used for transit peptide analysis (http://www.cbs.dtu.dk/ services/SignalP/).

\section{Statistical analysis and data handling}

Statistical analysis was carried out by IBM SPSS and least significant difference. Gray relational analysis was carried out by the DPS software ${ }^{71}$.

\section{Acknowledgements}

This work was sponsored by the Natural Science Foundation of Shanxi Province (201601D011077) and Shanxi Key Project in Agriculture (201803D221011-2)

\section{Author details \\ ${ }^{1}$ College of Horticulture, Shanxi Agricultural University, 030801 Taigu, Shanxi, China. ${ }^{2}$ College of Horticulture, Nanjing Agricultural University, 210095 Nangjing Jiangsu, China. ${ }^{3}$ Experimental Teaching Center, Shanxi Agricultural University, 030801 Taigu, Shanxi, China. ${ }^{4}$ College of Agriculture, Shanxi Agricultural University, 030801 Taigu, Shanxi, China. ${ }^{5}$ Plant \& Crop Sciences Division, School of Biosciences, University of Nottingham, Sutton Bonington Campus, Loughborough LE12 5RD, UK. ${ }^{6}$ Department of Horticulture, College of Agriculture \& Biotechnology, Zhejiang University, 310058 Hangzhou, China}

\section{Authors' contributions}

F.D., Y.-h.H. and D.G. conceived the experiments; T.W., J.-m.F., Z.-Z.L. and J.-x.Z. collected the samples; T.W., J.-m.F. and W.-X.F. conducted the experiments; T.W., J.-m.F. and Z.-z.L. analyzed the results; F.D. and D.G. wrote the manuscript.

\section{Data availability}

The raw data supporting the conclusions of this manuscript will be made available by the authors, without undue reservation, to any qualified researcher.

\section{Conflict of interest}

The authors declare that they have no conflict of interest.

Supplementary Information accompanies this paper at (https://doi.org/ 10.1038/s41438-019-0192-9).

Received: 1 March 2019 Revised: 3 June 2019 Accepted: 24 July 2019 Published online: 01 October 2019

\section{References}

1. Dudareva, N. \& Pichersky, E. Metabolic engineering of plant volatiles. Curr. Opin. Biotechnol. 19, 181-189 (2008).

2. Negre, F. et al. Regulation of methylbenzoate emission after pollination in snapdragon and petunia flowers. Plant Cell 15, 2992-3006 (2003).

3. Zeng, X. et al. Emission and accumulation of monoterpene and the key terpene synthase (TPS) associated with monoterpene biosynthesis in Osmanthus fragrans Lour. Front. Plant Sci. 6, 1232 (2015).

4. Kishimoto, K., Nakayama, M., Yagi, M., Onozaki, T. \& Oyama-Okubo, N. Evaluation of wild dianthus species as genetic resources for fragrant carnation breeding based on their floral scent composition. J. Jpn. Soc. Hortic. Sci. $\mathbf{8 0}$ 175-181 (2011).

5. Yang, X. et al. Analysis of floral scent emitted from Syringa plants. J. For. Res. 27, 273-281 (2015)

6. Maiti, S. \& Mitra, A. Morphological, physiological and ultrastructural changes in flowers explain the spatio-temporal emission of scent volatiles in Polianthes tuberosa L. Plant Cell Physiol. 58, 2095-2111 (2017).

7. Magnard, J. L. et al. Plant volatiles. Biosynthesis of monoterpene scent compounds in roses. Science 349, 81-83 (2015).

8. Salzmann, C. C., Cozzolino, S. \& Schiestl, F. P. Floral scent in food-deceptive orchids: species specificity and sources of variability. Plant Biol. (Stuttg.) $\mathbf{9}$, 720-729 (2007).

9. Morinaka, Y., Takatsu, Y. \& Hayashi, M. Sensory evaluation of floral scent in freesia (Freesia hybrida hort.) cultivars. J. Jpn. Soc. Hortic. Sci. 7, 702-709 (2002).

10. Blerot, B. et al. Functional analysis of four terpene synthases in rose-scented Pelargonium Cultivars (Pelargonium $\times$ hybridum) and evolution of scent in the Pelargonium genus. Front. Plant Sci. 9, 1435 (2018). 
11. Datta, S. K. Breeding of new ornamental varieties: rose. Curr. Sci. 114, 1194-1205 (2018).

12. Le Grice, B. E. Breeding blue and brown roses. R.N.R.S. Rose Annu. 124-127 (1969).

13. Oyama-Okubo, N. \& Tsuji, T. Analysis of floral scent compounds and classification by scent quality in tulip cultivars. J. Jpn. Soc. Hortic. Sci. 82, 344-353 (2013).

14. Johnson, T. S. et al. Lilium floral fragrance: a biochemical and genetic resource for aroma and flavor. Phytochemistry 122, 103-112 (2016).

15. Anderson, N. O. Flower Breeding and Genetics: Issues, Challenges and Opportunities for the 21st Century (Springer Science \& Business Media, 2006).

16. Lim, K.-B., Barba-Gonzalez, R., Zhou, S., Ramanna, M. \& Van Tuyl, J. M. Interspecific hybridization in lily (Lilium): taxonomic and commercial aspects of using species hybrids in breeding. Floric. Ornam. Plant Biotechnol. 5, 138-145 (2008).

17. Kong, Y., Sun, M., Pan, H.-t \& Zhang, Q.-x Composition and emission rhythm of floral scent volatiles from eight lily cut flowers. J. Am. Soc. Hortic. Sci. 137, 376-382 (2012).

18. Hui-xiu, Z., Zeng-hui, H., Ping-sheng, L., Wen-he, W. \& Fang, X. Qualitative and quantitative analysis of floral volatile components from different varieties of Lilium spp. Sci. Agric. Sin. 46, 790-799 (2013).

19. Morinaga, S.-I., Kumano, Y., Ota, A., Yamaoka, R. \& Sakai, S. Day-night fluctuations in floral scent and their effects on reproductive success in Lilium auratum. Popul. Ecol. 51, 187-195 (2008).

20. Hao, R. et al. A comparative analysis of characteristic floral scent compounds in Prunus mume and related species. Biosci. Biotechnol. Biochem. 78, 1640-1647 (2014).

21. Oyama-Okubo, N., Haketa, T., Furuichi, H. \& lioka, S. Characteristics of floral scent compounds in a new fragrant Petunia cultivar TX-794 'Evening Scentsation'. Hortic. J. 87, 258-263 (2018).

22. Clery, R. A., Owen, N. E. \& Chambers, S. F. An investigation into the scent of carnations. J. Essent. Oil Res. 11, 355-359 (1999).

23. $\mathrm{Hu}, \mathrm{Z}$. et al. Transcriptome sequencing analysis reveals a difference in monoterpene biosynthesis between scented Lilium 'Siberia' and unscented Lilium 'Novano'. Front. Plant Sci. 8, 1351 (2017).

24. Tholl, D. Biosynthesis and biological functions of terpenoids in plants. Adv. Biochem. Eng. Biotechnol. 148, 63-106 (2015).

25. Muhlemann, J. K. Klempien, A. \& Dudareva, N. Floral volatiles: from biosynthesis to function. Plant Cell Environ. 37, 1936-1949 (2014).

26. Filipe, A. et al. Molecular cloning and functional characterization of a monoterpene synthase isolated from the aromatic wild shrub Thymus albicans. J. Plant Physiol. 218, 35-44 (2017).

27. Borghi, M. \& Xie, D. Y. Cloning and characterization of a monoterpene synthase gene from flowers of Camelina sativa. Planta 247, 443-457 (2018).

28. Aros, D. et al. Volatile emissions of scented Alstroemeria genotypes are dominated by terpenes, and a myrcene synthase gene is highly expressed in scented Alstroemeria flowers. J. Exp. Bot. 63, 2739-2752 (2012).

29. Herde, M. et al. Identification and regulation of TPS04/GES, an Arabidopsis geranyllinalool synthase catalyzing the first step in the formation of the insect-induced volatile C16-homoterpene TMTT. Plant Cell 20, 1152-1168 (2008)

30. Calvert, J., Baten, A., Butler, J., Barkla, B. \& Shepherd, M. Terpene synthase genes in Melaleuca alternifolia: comparative analysis of lineage-specific subfamily variation within Myrtaceae. Plant Syst. Evol. 304, 111-121 (2017).

31. Keszei, A., Hassan, Y. \& Foley, W. J. A biochemical interpretation of terpene chemotypes in Melaleuca alternifolia. J. Chem. Ecol. 36, 652-661 (2010).

32. Chen, F., Tholl, D., Bohlmann, J. \& Pichersky, E. The family of terpene synthases in plants: a mid-size family of genes for specialized metabolism that is highly diversified throughout the kingdom. Plant J. 66, 212-229 (2011).

33. Kulheim, C. et al. The Eucalyptus terpene synthase gene family. BMC Genomics 16, 450 (2015).

34. Degenhardt, J., Kollner, T. G. \& Gershenzon, J. Monoterpene and sesquiterpene synthases and the origin of terpene skeletal diversity in plants. Phytochemistry 70, 1621-1637 (2009).

35. Steele, C. L., Crock, J., Bohlmann, Jr \& Croteau, R. Sesquiterpene synthases from Grand Fir (Abies grandis). J. Biol. Chem. 273, 2078-2089 (1998).

36. Pazouki, L. \& Niinemets, Ü. Multi-substrate terpene synthases: their occurrence and physiological significance. Front. Plant Sci. 7, 1019 (2016).

37. Zhang, T. X. et al. Molecular cloning and expression analysis of a monoterpene synthase gene involved in floral scent production in lily (Lilium 'Siberia'). Russ. J. Plant Physiol. 64, 600-607 (2017).
38. Huang, Y., Yang, H., Qi, X., Malekian, R., Pfeiffer, O. \& Li, Z. A novel selection method of seismic attributes based on gray relational degree and support vector machine. PLOS ONE 13, e0192407 (2018).

39. $\mathrm{Xu}, \mathrm{Q} . \& \mathrm{Xu}, \mathrm{K}$. Mine safety assessment using gray relational analysis and bow tie model. PLOS ONE 13, e0193576 (2018).

40. Rehman, R., Hanif, M. A., Mushtaq, Z. \& Al-Sadi, A. M. Biosynthesis of essential oils in aromatic plants: a review. Food Rev. Int. 32, 117-160 (2015).

41. Poinar, G. \& Poinar, G. The antiquity of floral secretory tissues that provide today's fragrances. Historical Biol. https://doi.org/10.1080/ 08912963.2018 .1502288 (2018).

42. Kolosova, N., Sherman, D., Karlson, D. \& Dudarev, N. Cellular and subcellular localization of S-adenosyl-I-methionine: benzoic acid carboxyl methyltransferase, the enzyme responsible for biosynthesis of the volatile ester methylbenzoate in snapdragon flowers. Plant Physiol. 126, 956-964 (2001).

43. Scalliet, $G$. et al. Role of petal-specific orcinol O-methyltransferases in the evolution of rose scent. Plant Physiol. 140, 18-29 (2006).

44. Bergougnoux, $\vee$. et al. Both the adaxial and abaxial epidermal layers of the rose petal emit volatile scent compounds. Planta 226, 853-866 (2007).

45. Li, W.-q Flavor and flavor styles of liquor. Liquor Mak. 34, 5-7 (2007).

46. Yuanju, T. On aroma type of flue-cured tobacco [J]. Chin. Tob. Sci. 32, 1-7 (2011).

47. Yamashita, I., lino, K., Nemoto, Y. \& Yoshikawa, S. Studies on flavor development in strawberries. 4. Biosynthesis of volatile alcohol and esters from aldehyde during ripening. J. Agric. Food Chem. 25, 1165-1168 (1977).

48. Yang, $X$. et al. Associations between the 1-deoxy-d-xylulose-5-phosphate synthase gene and aroma in different grapevine varieties. Genes Genomics $\mathbf{3 9}$, 1059-1067 (2017)

49. Yomogida, K. Scent of modern roses. Koryo 175, 65-89 (1992).

50. Pino, J. A., Marbot, R. \& Va'zquez, C. Characterization of volatiles in strawberry guava (Psidium cattleianum Sabine) Fruit. J. Agric. Food Chem. 49, 5883-5887 (2001).

51. Kumar, B. et al. Association analysis of single nucleotide polymorphisms in candidate genes with root traits in maize (Zea mays L.) seedlings. Plant Sci. 224, 9-19 (2014).

52. Choi, I. Y. et al. A soybean transcript map: gene distribution, haplotype and single-nucleotide polymorphism analysis. Genetics 176, 685-696 (2007).

53. Li, Y. et al. High levels of nucleotide diversity and fast decline of linkage disequilibrium in rye (Secale cereale L.) genes involved in frost response. BMC Plant Biol. 11, https://doi.org/10.1186/1471-2229-11-6 (2011).

54. Zein, I., Wenzel, G., Andersen, J. R. \& Lübberstedt, T. Low Level of Linkage Disequilibrium at the COMT (Caffeic Acid O-methyl Transferase) Locus in European Maize (Zea mays L.). Genet. Resour. Crop Evol. 54, 139-148 (2006).

55. Chang, Y.-T. \& Chu, F.-H. Molecular cloning and characterization of monoterpene synthases from Litsea cubeba (Lour.) Persoon. Tree Genet. Genomes 7, 835-844 (2011)

56. Alquézar, B., Rodríguez, A., de la Peña, M. \& Peña, L. Genomic analysis of terpene synthase family and functional characterization of seven sesquiterpene synthases from Citrus sinensis. Front. Plant Sci. 8, 1481 (2017).

57. Abbas, F., Ke, Y., Yu, R. \& Fan, Y. Functional characterization and expression analysis of two terpene synthases involved in floral scent formation in Lilium 'Siberia'. Planta 249, 71-93 (2019).

58. Demissie, Z. A. et al. Cloning, functional characterization and genomic organization of 1, 8-cineole synthases from Lavandula. Plant Mol. Biol. 79, 393-411 (2012).

59. Mount, S. M. Genomic sequence, splicing, and gene annotation. Am. J. Hum. Genet. 67, 788-792 (2000).

60. Trapp, S. C. \& Croteau, R. B. Genomic organization of plant terpene synthases and molecular evolutionary implications. Genetics 158, 811-832 (2001).

61. Martin, D. M. et al. Functional annotation, genome organization and phylogeny of the grapevine (Vitis vinifera) terpene synthase gene family based on genome assembly, FLCDNA cloning, and enzyme assays. BMC Plant Biol. 10 226 (2010).

62. Shimada, T. et al. Molecular cloning and functional characterization of four monoterpene synthase genes from Citrus unshiu Marc. Plant Sci. 166, 49-58 (2004).

63. Starks, C. M. Structural basis for cyclic terpene biosynthesis by tobacco 5-EpiAristolochene synthase. Science 277, 1815-1820 (1997).

64. Dudareva, N. (E)-beta-Ocimeneand Myrcene synthase genes of floral scent biosynthesis in snapdragon: function and expression of three terpene synthase genes of a new terpene synthase subfamily. Plant Cell Online 15, 1227-1241 (2003) 
65. Chen, F. Characterization of a root-specific Arabidopsis terpene synthase responsible for the formation of the volatile monoterpene 1,8-Cineole. Plant Physiol. 135, 1956-1966 (2004).

66. Turner, G., Gershenzon, J., Nielson, E. E., Froehlich, J. E. \& Croteau, R. Limonene synthase, the enzyme responsible for monoterpene biosynthesis in peppermint, is localized to leucoplasts of oil gland secretory cells. Plant Physiol. 120 879-886 (1999)

67. Mendoza-Poudereux, I. et al. Metabolic cross-talk between pathways of terpenoid backbone biosynthesis in spike lavender. Plant Physiol. Biochem. 95 113-120 (2015)
68. Feng, L. et al. Flowery odor formation revealed by differential expression of monoterpene biosynthetic genes and monoterpene accumulation in rose (Rosa rugosa Thunb.). Plant Physiol. Biochem. 75, 80-88 (2014).

69. Burdock, G. A. Fenaroli's Handbook of Flavor Ingredients (CRC press, 2016).

70. Dellaporta, S. L., Wood, J. \& Hicks, J. B. A rapid method for DNA extraction from plant tissue. Plant Mol. Biol. Rep. 1, 19-21 (1983).

71. Tang, Q. Y. \& Zhang, C. X. Data Processing System (DPS) software with experimental design, statistical analysis and data mining developed for use in entomological research. Insect Sci. 20, 254-260 (2013). 